Mediscope

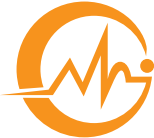

The Journal of GMC

\title{
Early results of different types of anorectoplasty for anorectal malformations
}

\author{
${ }^{*}$ M Rahman', T Islam², Z Sharif ${ }^{3}$, MD Akhter ${ }^{4}$
}

\begin{abstract}
Objective: To document our experience with the technique of surgical repair in anorectal malformations (ARM) and the short term anatomical and functional outcomes. Methods: This study included total 31 babies. Fourteen were perineal fistula cases with age range between 1 to 4 days. Ten patients had vestibular fistula and seven had rectourinary fistula. Primary diverting colostomy was done for vestibular and rectourinary fistula patients. On the other hand low imperforate anus with anoperineal fistula without associated major anomalies had undergone fistulectomy and simple anoplasty. Results: Simple anoplasty was done for fourteen perineal fistula cases. Anterior sagittal anorectoplasty (ASARP) was done for 10 vestibular fistulae and posterior sagittal anorectoplasty (PSARP) was done in 10 recto-urinary fistula cases. Simple anoplasty and vestibular anus scored good (5-6) in $70 \%$ to $71 \%$ while PSARP scored fair in $58 \%$ of the cases. Postoperative mucosal prolapse, anal stenosis and retraction occurred in two, six and one patient respectively. Redo surgery was done in mucosal prolapse and retraction cases. Four responded to anal dilation and the other needed redo surgery by a simple cutback technique for anal stricture. Continence was assessed in 23 patients whose follow-up periods were longer than 3 years. Twenty one patients had a good score and two had a fair score. No patients had a poor score. Conclusion: Our approach has the following advantages: (i) The operative technique is simple and easy to perform. (ii) Minimal complication rate with good cosmetic results.
\end{abstract}

\section{Introduction}

Anorectal malformations (ARMs) encompass a spectrum of congenital anomalies involving the rectum, urinary tract, and the reproductive structures with varying degrees of complexity. It has been continuing to present a challenge for the pediatric surgeons. Presentations may vary from simple low malforma- tions like perineal fistula which can be treated by simple cutback anoplasty to high complex malformations which requires difficult and challenging multi-staged operative procedures. The average incidence is around 1:2000-2500 births. ${ }^{1-3}$ Survival among ARM patients over the last few decades have greatly improved due to

1. Dr. Mizanur Rahman, Associate Professor, Department of pediatric Surgery, Khulna Medical College Hospital, Khulna. Email: dr.mizanur64@yahoo.com.

2. Dr. Tarikul Islam, Associate professor, Department of Burn \& plastic surgery, Khulna Medical College Hospital, Khulna.

3. Dr. Zafor Sharif, Assistant Professor, Department of Pediatric Surgery, Khulna Medical College Hospital, Khulna.

4. Dr. Most. Dalia Akhter, Assistant Professor, Department of Gynaecology \& Obstetrics, Khulna Medical College Hospital, Khulna. 
advances in modern surgical techniques and neonatal care, and early mortality is now unusual in the absence of fatal associated cardiac or chromosomal defects. ${ }^{4}$ Earlier, the aim of surgical care was limited only to the survival of the patient but nowadays the focus has changed to help children grow up with good bowel function that is compatible with a good quality of life, 5 so that the children are being able to actively participate in their social context without significant abnormality in their bowel functions, where fecal continence is a major determinant. ${ }^{6}$

In 1982, De Vries and Peña first introduced posterior sagittal anorectoplasty (PSARP) and followed later by its limited modification in the technique of operation, anterior sagittal anorectoplasty (ASARP) represents the basis of the modern surgical approach to ARMs with termination of the anal canal outside the voluntary sphincter complex. PSARP represents the exposure of structures under direct vision and restoration of the normal anatomical relationships between structures. It is the well established and the gold standard procedure for the definitive treatment of ARM patients. ${ }^{7-9}$

This study was performed to document our experience in the short-term results and to evaluate early anatomical and functional outcomes of anoplasty and ASARP/PSARP in ARM patients.

\section{Methodology}

Neonates and children with perineal fistula (PF), vestibular fistula (VF), recto-urinary fistula were identified and operated in Khulna Medical College Hospital (KMCH) and other tertiary care hospitals in Khulna city from November 2013 to April 2018. Follow up period was 8 months to 5 years (short term). Patients with major congenital abnormalities e.g. persistent cloaca, Currarino syndrome, total sacral agenesis (caudal regression syndrome) or menigomyelocele were excluded.

A total of 31 patients participated in the study, including 14 male babies (45.16\%) presented with low ARM, 7 male babies $(22.58 \%)$ with more severe high malformations, and 10 female babies (32.2\%) with vestibular fistula (Table 01). The Proper clinical record including history and physical examination of the patients to assess the type of anomaly and other associated congenital defects was maintained.

\section{Surgical procedures}

Simple anoplasty was done in male babies having perineal fistulas (low ARM) without initial colostomy. Remaining male and female babies having recto-urinary fistulas and vestibular fistula underwent staged operation. After a minimum of six months interval from primary colostomy, PSARP in recto-urinary and ASARP in vestibular fistula were done. Colostomy was closed at least six months later from $2^{\text {nd }}$ operation. Gradual recto-anal calibration started 2 weeks after $2^{\text {nd }}$ stage or definitive operation and continued until the anus became pliable.

\section{Measurement of outcomes}

Over the years, many different scoring systems have been employed for the evaluation of outcomes following the surgical treatment of ARMs, which has presented challenges for the later comparison of outcomes between series. Historically, Kelly's method ${ }^{10}$ defined outcomes as "good," "fair," or "poor" based on the presence or absence of fecal continence, perineal staining and Sphincter tension

\section{Kelly's method ${ }^{10}$}

\begin{tabular}{|l|c|c|}
\hline Parameter & Effect & Score \\
\hline Continence & & \\
\cline { 2 - 3 } & Normal, no soiling & 2 \\
\cline { 2 - 3 } & $\begin{array}{c}\text { Occasional accidents, } \\
\text { feces/flatus escape }\end{array}$ & 1 \\
\cline { 2 - 3 } & No control, frequent accidents & 0 \\
\hline \multirow{5}{*}{ Staining } & & 2 \\
\cline { 2 - 3 } & Always clean & 1 \\
\cline { 2 - 3 } & Occasional staining & 0 \\
\cline { 2 - 3 } & Always stained & 2 \\
\hline Sphincter & & 1 \\
\cline { 2 - 3 } & Strong and effective squeeze & 2 \\
\cline { 2 - 3 } & Weak and partial squeeze & 1 \\
\cline { 2 - 3 } & No contraction & 0 \\
\hline
\end{tabular}




\section{Results}

A total of 31 patients participated in the study, including 21 male and 10 female patients. Male- female ratio is 2.1:1. Fourteen male babies $(45.16 \%)$ presented with perineal fistula, 10 (32.2\%) female with vestibular anus and 7 male (22.58\%) with more severe recto urinary malformations (Table 01).

Table 01: Types of ARM

\begin{tabular}{|l|l|l|l|}
\hline \multirow{2}{*}{ Type of ARM } & \multicolumn{2}{|c|}{$\begin{array}{c}\text { Number } \\
\text { of cases }\end{array}$} & \multirow{2}{*}{ Percentage } \\
\cline { 2 - 4 } & Male & Female & \\
\hline Perineal fistula (low) & 14 & & $45.16 \%$ \\
\hline Vestibular fistula & & 10 & $32.2 \%$ \\
\hline Recto urinary fistula (high) & 07 & & $22.58 \%$ \\
\hline Total & 31 & & $100 \%$ \\
\hline
\end{tabular}

Table 02: Types of surgical procedures

\begin{tabular}{|l|l|l|l|l|}
\hline $\begin{array}{l}\text { Type of } \\
\text { surgery } \\
\text { done }\end{array}$ & $\begin{array}{l}\text { Perineal } \\
\text { fistula }\end{array}$ & $\begin{array}{l}\text { Vestibular } \\
\text { Anus }\end{array}$ & $\begin{array}{l}\text { Recto } \\
\text { Urinary } \\
\text { Fistula } \\
07\end{array}$ & $\begin{array}{l}\text { Perc- } \\
\text { entage }\end{array}$ \\
\hline $\begin{array}{l}\text { Simple } \\
\text { Anoplasty }\end{array}$ & 14 & 10 & 07 & $100 \%$ \\
\hline ASARP & & 10 & $100 \%$ \\
\hline PSARP & & & 07 & $100 \%$ \\
\hline Total & & & & 31 \\
\hline
\end{tabular}

Simple anoplasty was done in fourteen perineal fistula cases. The age of anoplasty was 1 to 3 days. Seven patients having recto-urinary fistula underwent PSARP and ten patients having vestibular fistula underwent ASARP. The median age of surgical procedure was $18 \pm 3$ months.
Table 03: Outcome of surgical procedures

\begin{tabular}{|l|l|l|l|}
\hline $\begin{array}{l}\text { Type of } \\
\text { operation }\end{array}$ & $\begin{array}{l}\text { No. of } \\
\text { patients }\end{array}$ & $\begin{array}{l}\text { Kelly' s } \\
\text { score }\end{array}$ & $\begin{array}{l}\text { Outcome } \\
(\%)\end{array}$ \\
\hline Anoplasty & 14 & $\begin{array}{l}5-6 \text { (good) } \\
3-4 \text { (fair) } \\
0-2 \text { (Poor) }\end{array}$ & $\begin{array}{l}04(29 \%) \\
00\end{array}$ \\
\hline ASARP & 10 & $\begin{array}{l}5-6 \text { (good) } \\
3-4 \text { (fair) }\end{array}$ & $07(70 \%)$ \\
& & $\begin{array}{l}0-2 \text { (Poor) } \\
0\end{array}$ & 00 \\
\hline PSARP & 07 & $\begin{array}{l}5-6 \text { (good) } \\
3-4 \text { (fair) }\end{array}$ & $04(58 \%)$ \\
& & $\begin{array}{l}0-2 \text { (Poor) } \\
0\end{array}$ & 00 \\
\hline
\end{tabular}

Those who underwent simple anoplasty for perineal fistula (low ARM), 71\% scored 5-6 (good) and remaining scored 3-4 (fair). Seven patients $(70 \%)$ scored $5-6$ (good) out of ten and $30 \%$ scored $3-4$ in the remaining for ASARP. For PSARP, four patients (58\%) scored 5-6 (good) and three patients scored 3-4 (fair). None of the groups scored poor.

Table 04: Complications of surgery $(n=31)$

\begin{tabular}{|c|c|c|c|c|}
\hline Complications & $\begin{array}{l}\text { Anoplasty } \\
(n=14)\end{array}$ & $\begin{array}{l}\text { ASARP } \\
(n=10)\end{array}$ & $\begin{array}{l}\text { PASRP } \\
(\mathrm{n}=07)\end{array}$ & No $(\%)$ \\
\hline $\begin{array}{l}\text { Mucosal } \\
\text { prolapse }\end{array}$ & 00 & 00 & 02 & $6.45 \%$ \\
\hline $\begin{array}{l}\text { Vaginal } \\
\text { perforation }\end{array}$ & 00 & 00 & 00 & 00 \\
\hline $\begin{array}{l}\text { Vaginal } \\
\text { stenosis }\end{array}$ & 00 & 00 & 00 & 00 \\
\hline $\begin{array}{l}\text { Retraction of } \\
\text { neoanus }\end{array}$ & 00 & 01 & 00 & $3.22 \%$ \\
\hline Urethral injury & 00 & 00 & 00 & 00 \\
\hline Anal stenosis & 00 & 00 & 02 & $6.45 \%$ \\
\hline
\end{tabular}


Two mucosal prolapse and two anal stenosis were developed after PSARP. In one case, retraction of the anus occurred for ASARP in vestibular anus. No complications were found after simple anoplasty.

\section{Discussion}

The management of infants with ARM continues to be a challenge for the pediatric surgeons worldwide. For optimal results, careful preservation of structures and precise anatomical reconstruction is required.

Perineal fistula is the most common type of ARM and is treated by simple anoplasty. It is associated with good prognosis. ${ }^{11}$ On the other hand, vestibular fistula and recto-urinary fistula comprise more complicated surgery i.e. ASARP/PSARP and is associated with more or less poor prognosis. For the last 15-20 years, PSARP has been the gold standard of all the procedures performed in the past for the treatment of anorectal malformations. ${ }^{12}$

Over a period of four years, we have applied this procedure on 31 children with low and high anorectal malformations, finding good anatomical results. The immediate anatomical appearance of the neo-anus and perineum has been satisfactory. To avoid complications, the operation requires a good understanding of the anatomy of the pelvis and the perineum, good surgical skills and patience. In the developed world, usually the operation is carried out in the immediate neonatal period, without the use of colostomy with the aim of better functional outcome, probably from the early development of the necessary cortico-anal somato-sensory integration, which may be lost in those patients who had a diverting colostomy. ${ }^{13}$

We treated our patients with colostomy before surgery with the aim of life-saving measure and to divert feces to avoid wound infection. Moreover, the sphincter muscle complex requires identifying and dividing in the midline. This can be better done by the use of Pena's muscle stimulator. However, this is not available in our unit. We rely on visual identification and low diathermy stimulation of the muscle complex at operation. This is very low cost and easy to perform.

The short-term functional outcome of anoplasty was good. A majority of patients reaching 3 to 5 years were able to maintain their bowel movement. Using the Kelly's scoring system in all patients of our series, 21 had a good score i.e. good anal sphincter function and bowel continent. Ten cases had a fair score i.e. sphincter function and bowel continent is within normal limit. None had poor score (Kelly's score). These are consistent with other studies. ${ }^{1}$

The immediate anatomical appearance of the neo-anus and perineum has been satisfactory. The functional clinical outcomes of posterior sagittal ano-rectoplasty recorded during follow up showed that the majority of children were either totally continent or had good voluntary bowel control corresponding with their ages which is similar to the experiences of other authors. The frequencies of anal stenosis and incontinence recorded were also similar to common anal dysfunctions recorded in other studies. ${ }^{12,15}$

\section{Conclusion}

It can be concluded that anoplasty for perineal fistula is simple and easy to perform. ASARP/PSARP is the useful procedure for the correction of vestibular and recto-urinary fistulas (high $A R M$ ) in children in our settings even in the absence of muscle stimulator. The short-term anatomical and functional outcome is satisfactory. Long-term follow up is mandatory for further and better evaluation. 


\section{References}

1. Kyrklund K, Anorectal MalformationsOutcomes up to adulthood. Academic thesis. University of Helsinki, Publ. Helsinki, Finland: 2015; 55: 671-676.ternatioedical Research

2. K. Jayapal, Chanda Bhaskara Rao, G. Hasanthi, J.S. Kishore, R. Suman, Bhavana Chanda. Cross sectional study of results of postoperative recto-vestibular fistula patients. International Journal of Contemporary Medical Research 2017;4(11):2324-2328.

3. Amanollahi $\mathrm{O}$, Ketabchian $\mathrm{S}$, One-stage vs. three-stage repair in anorectal malformation with recto-vestibular fistula Afr J Paediatr Surg. 2016 Jan-; 13: 20-25.

4. Rintala RJ, Pakarinen MP. Imperforate anus: long- and short-term outcome. Semin Pediatr Surg 2013; 17: 79-89.

5. Iwai N, Fumino S. Surgical treatment of anorectal malformations. Surg Today 2013; 43: 955-962.

6. Goyal A, Williams JM, Kenny SE, Lwin R, Baillie CT, Lamont GL, Turnock RR. Functional outcome and quality of life in anorectal malformations. J Pediatr Surg 2014; 41: 318-322.

7. De Vries PA, Peña A. Posterior sagittal anorectoplasty. J Pediatr Surg1982; 17: 638- 643.

8. Khan K, Anorectal Malformations: Functional Outcomes of Posterior Sagittal Anorecto- plasty, JPMI: 2014 vol.22 no.4: 304-8.
9. Okada A, Tamada H, Tsuji H, Azuma T, Yagi M, Kubota A, Kamata S. Anterior sagittal anorectoplasty for rectovestibular and anovestibular fistula. J Pediatr Surg2013; 27: 85-88.

10. Kelly $\mathrm{JH}$. The clinical and radiological assessment of anal continence in childhood. Aus N Z J Surg1972; 42: 62-63.

11. Rosen NG, Beals DA. Imperforate anus. 2010; Available at: http:// emedicine. medscape.com/article/929904-overview. [Accessed on 12 February 2010]

12. Osifo OD, Osagie TO, Udefiagbon EO. Outcome of primary posterior sagittal anorectoplasty of high anorectal malformation in well selected neonates. Niger J Clin Pract 2014; 17: 1-5.

13. O. A. Sowande, O. Adejuyigbe, O. I. Alatise, U. E. Usang. Early results of the posterior saggital anorectoplasty in the treatment of anorectal malformations in Nigerian children. J Indian Assoc Pediatr Surg / Apr-June 2006 / Vol 11 / Issue 2.

14. Pena A, Devries PA. Posterior sagittal anorectoplasty: Important technical considerations and new applications. J Pediatr Surg 1982;17:796-811.

15. Ibrahim Al. Fistulectomy and anoplasty for low imperforate anus with anoperineal fistula in boys, 1687-4137 _c 2011 Annals of Pediatric Surgery. 